\title{
O fandango de chilenas e suas transformações no tempo
}

\author{
BRUNO DE SOUZA SANCHES ${ }^{I}$
}

$\mathrm{N}$ O BRASIL, é bastante comum lidarmos com termos polissêmicos no âmbito da música. É corriqueiro utilizarmos vários nomes distintos para tratar de um mesmo ritmo, estilo ou instrumento musical. A palavra fandango é utilizada atualmente para designar quatro ${ }^{1}$ tipos de bailados diferentes no Brasil, e para se referir aos fandangos há aproximadamente cinquenta expressões utilizadas pelo povo brasileiro (Fryer, 2000). Aparece, normalmente, em três regiões do país, com características diversas, como um conjunto de danças - sinônimo de baile.

Na região Nordeste, especialmente no estado de Alagoas, há a marujada, chegança, chegança de marujos ou barca, que é um conjunto de danças dramáticas, também conhecido como fandango; na região Sul, no estado do Rio Grande do Sul, o fandango não constitui um ritmo específico, mas um conjunto de danças que compõem um baile: “Chamou-se 'fandango', no antigo Rio Grande, a uma série de cantigas entremeadas de sapateio" (Côrtes; Lessa, 1961, p.9); Nas regiões Sul e Sudeste, no litoral dos estados de São Paulo e Paraná, há o fandango caiçara, também chamado de "Bate-pé (Batuque), Chiba, Fandango, Função e Baile” (Lima et al., 1981, p.181); na região Sudeste, no interior paulista, há três tipos de fandangos caipiras.

Os fandangos caipiras estão presentes na macrorregião de Sorocaba, região sudoeste do estado de São Paulo, e são heranças do tropeirismo. São eles: Fandango de chilenas ${ }^{2}$ presente em Angatuba, Campina do Monte Alegre, Capela do Alto, Itapetininga e Tatuí; Fandango de botinas, ${ }^{3}$ presente apenas na zona rural de Itapetininga; e Fandango de tamancos, ${ }^{4}$ presente em Ribeirão Grande.

Os fandangos de chilenas e de botinas são musicalmente muito parecidos, ${ }^{5}$ mas o fandango de tamancos em muito se difere deles. ${ }^{6}$ A estrutura formal básica da música de todos é semelhante e por isso os classificamos como fandangos caipiras, mas neste artigo escolhemos nos ater ao fandango de chilenas, por ser o que possui mais evidência na região, apresenta projeção além dela e está mencionado na literatura. ${ }^{7}$ Essa menção, contudo, é extremamente modesta, pois há somente um texto, de Rossini Tavares de Lima (1954), que fala sobre os fandangos de chilenas de maneira adequada, pois registra sua ocorrência geográfica, principais ritmos e marcas $^{8}$ praticadas, no entanto deixa a desejar musicalmente, pois não apresenta partituras completas das danças, que poderiam nos informar sobre a forma musical, tampouco mostra as harmonias implicadas nos rasgueados das violas. 
Para sanar essas lacunas na bibliografia, estamos elaborando estudos musicais sobre os fandangos caipiras que serão publicados oportunamente. Como a pesquisa está em processo de desenvolvimento, este artigo possui um caráter ensaístico, pois apresentaremos alguns caminhos para os quais apontam nossos estudos, mas nem sempre chegaremos a conclusões decisivas sobre o assunto. Encontramos na literatura, além do texto de Lima, algumas referências confusas sobre o fandango de chilenas e optamos, então, por esclarecer algumas destas questões neste artigo.

Enquanto fazíamos uma busca minuciosa pelos principais trabalhos sobre o folclore brasileiro, percebemos que há uma mixórdia com os termos cateretê/ catira $^{9}$ e fandango. Parece possível afirmar que a falta de bibliografia sobre os fandangos caipiras deve-se principalmente à confusão existente desde antanho entre essas duas danças, como mostraremos a seguir.

No Dicionário Musical Brasileiro, de Mário de Andrade, o verbete Fandango traz a seguinte informação, obtida através de Afonso Vergueiro a respeito dos bailados de Sorocaba:

Fandango - a palavra tem dois sentidos: um, o de "reunião onde há dança" e o de uma determinada dança que se confunde com o cateretê. Assim confundida existe aqui. (Inquérito sobre Costumes e Superstições da Sociedade de Etnografia e Folclore do Departamento de Cultura, carta de 23 de abril de 1937 - Série Recortes, 7, Arquivo Mário de Andrade, IEB-USP). (Andrade, 1989, p.236)

Essa informação foi obtida por Andrade no ano de 1937. Fica, então, a seguinte dúvida: confundida por quem pesquisa ou por quem pratica o fandango? Saber a resposta a essa pergunta seria de grande valia: se os termos causassem confusão entre os próprios praticantes, isso seria sinal de sinonímia entre as expressões, pois - como sabemos - é comum no Brasil haver mais de um termo para se referir a uma só prática ou instrumento musical. No entanto, se a confusão é feita pelos pesquisadores, então isso mostraria que há muito não há clareza entre os estudiosos da cultura popular sobre a diferença entre o catira e os fandangos de esporas.

Ainda no dicionário de Mário de Andrade, sobre o verbete bate-pé: "Uma das denominações do cateretê. 2. Algumas vezes usado como sinônimo de fandango, baile, arrasta-pé" (Andrade, 1989, p.51), o que aponta o uso de uma mesma expressão para ambas as danças, por questões óbvias, são danças de sapateado. Mais adiante, sobre o verbete quebra-espora: "nome que se dá, em Sorocaba, a um dos passos do cateretê" (Andrade, 1989, p.416), imagino que se refira à mesma marca do fandango, ou semelhante, que hoje chamam de quebra-chifre na região. Há também uma marca do fandango executada ainda em Tatuí e Capela do Alto e que também foi presente em Itapetininga, pelo que me contaram os dançadores, chamada Mandadinho. Pela descrição que fizeram os fandangueiros de Itapetininga, seria exatamente o que explana Mario de Andrade no verbete mandado: 
MANDADO - Dança sapateada, variante do cateretê. Cornélio Pires, que assistiu a ela em Tatuí (SP), descreve: "é um sapateado com marcação como 'Quadrilha"'. Os sapateadores atendem ao marcante, com gestos e ruídos dos pés e mãos, conforme são "mandados". Eis algumas das marcas: "Tira-cipó”! "O Tatu faz buraco"! “Aventá arrois"! "Espaia cisco"! "Juntô nas chilena"! "Bate machado"! E outras mais. (Andrade, 1989, p.300)

Em todos os verbetes mencionados, a referência é sempre feita ao cateretê - e não ao fandango. $\mathrm{O}$ mesmo ocorre com a maioria dos livros que tratam desses bate-pés. No Documentário Folclórico Paulista, de Alceu Maynard Araújo, chama a atenção quando vemos registrados como indumentária do cateretê, tamancos idênticos aos caiçaras, bem como chilenas, utilizadas no fandango (Araújo, 1952, p.21). E ainda, em seu livro Folclore Nacional II, sobre o cateretê:

Na parte média da região de Ubá, desde Angra dos Reis (estado do Rio de Janeiro) até baía de Paranaguá (estado do Paraná), ele é dançado com tamancos de madeira dura. Nas Zonas Pastoris (Guaratinguetá, Itararé e sul do estado de São Paulo, Piraí, no estado do Paraná), usam grandes esporas "chilenas" para retinir, em Taubaté, Cunha, São Luis do Paraitinga, Natividade da Serra, Redenção da Serra, Jambeiro, São Pedro de Catuçaba, Lagoinha, nas danças de que temos participado, quase todos dançam descalços. [...] Em Nazaré Paulista, Piracaia, chamam-na catira, havendo algumas pessoas nesses lugares que também a chamavam de cateretê. Em Cunha, tivemos oportunidade, por diversas vezes, de tomar parte nessa dança, que chamam de xiba. Em Tietê, Tatuí, Porongaba, Itapetininga e Taubaté, chamam-na de cateretê. Essa é a denominação mais encontrada. Aluísio de Almeida, pseudônimo do cônego Luís Castanho de Almeida, em Danças caipiras, além de confirmar a baralhada que fazem com a denominação dessa dança, afirma que sua área se estende de Sorocaba a Cruz Alta, no estado do Rio Grande do Sul, presente portanto, na região campeira. Leiamos:

"O bate-pé, racha-pé, sapateado, cateretê, cateretê mineiro, fandango considerado como dança especial, são tão semelhantes entre si, que não passam de uma variante da mesma dança. A diferença pode estar na velocidade com que os pés batem no chão tal como o sapateado tatuiano, que é ligeirinho como quê! O ritmo, obtido pelas chilenas, grandes rosetas de esporas dos antigos tropeiros sorocabanos. Ao levantar do chão, os dois pés em conjunto, o dançador une os calcanhares, de sorte que uma chilena se choque com a outra. É preciso lembrar que as esporas eram de prata, donde, além do ritmo, o som agradável. A área geográfica dessa modalidade do bate-pé ia de Sorocaba a Cruz Alta, no Rio Grande do Sul, e ainda há pouco foi possível realizar uma demonstração. Além disso foi dança de um grupo social, dos tropeiros. Documentos abundantes mostram que, desde Cubatão até o Interior mais distante, os tropeiros, de tropa arriada e de animais chucros, transformavam os pousos e ranchos em sedes de danças por eles preferidas, quase sempre o bate-pé”. (Araújo, 2004, p.133-4) 
Nesse texto de Araújo fica nítida a opção do autor em considerar toda forma de bate-pé como cateretê; assim o fandango remanescente do tropeirismo na região sudoeste paulista fica considerado como uma das variações do cateretê. Em outro texto sobre o fandango, Araújo traz a seguinte afirmação, baseado em sua pesquisa sobre os ciclos do fandango:

Pelos antigos caminhos de tropas, hoje já não dançam mais o fandango; persiste porém a prática do cateretê. Acontece que a este chamam-no de fandango, como registramos em Tatuí, Quadra, Guareí, Araçoiaba da Serra; onde a urbanização e principalmente o desejo de exibir-se em palanques oficiais, introduziram novidades no cateretê, afandangando-o. (Araújo, 2004, p.214)

Veja que essa afirmação contradiz a que foi dada na página 133 , pois lá diz que em Tatuí chamam a dança de cateretê e aqui diz que praticam o cateretê, mas chamam-na de fandango.

Todo o trecho de seu livro em que se refere ao fandango trata sobre o fandango caiçara e sobre o fandango que vem da Europa, trazido pelos portugueses (Araújo, 2004, p.144, 145 e 211). O autor não percebe que há outro tipo de fandango na região caipira e, portanto, parece-nos que a afirmação supracitada (ibidem, p.214) não passa de mais uma confusão terminológica, pois ele julga que o equívoco de nomenclatura ocorre em toda a região a que se refere, pelos próprios praticantes.

Não fosse o estudo de Lima (1954) sobre o tema, registrando algumas características dos fandangos caipiras que notamos até hoje, essas afirmações confusas na bibliografia nos deixariam muitas dúvidas. Ficaria a impressão de que - na época em que foram feitas as pesquisas - o fandango e o cateretê teriam sido muito semelhantes. Segue, então, trecho do estudo de Lima:

No Estado de São Paulo, possuímos dois tipos de fandango: o do interior sul e o da região litorânea.

O do interior sul, observamos entre remanescentes do tropeiro paulista nas regiões rurais de Tatuí, S. Miguel Arcanjo, Guareí, Capela do Alto, Cesário Lange, Itararé e Sarapuí.

Em Tatuí, o fandango compreende uma série de "marcas", como "quebra-chifre", "pega na bota", "vira corpo", "pula sela" e "mandadinho". Participam da dança um número par de dançadores, todos homens, geralmente dez ou doze. A indumentária compreende calça comum, botins, ${ }^{10}$ camisa arregaçada nos braços, lenço no pescoço e chapéu na cabeça. Nos botins, usam chilenas de duas rosetas, sem dentes, que durante a dança, funcionam como instrumentos musicais idiofones, ${ }^{11}$ e que os dançadores mandam fazer especialmente para o fandango. Do lado de fora da roda, que formam os fandangueiros, fica o violeiro e seu "segunda", que canta uma terça acima ou abaixo da melodia principal. A função do violeiro é tocar o "rasqueado" para dançar e cantar trechos de uma moda de viola, nos intervalos das "marcas". 
Todas as "marcas" do Fandango são rodadas da esquerda pra direita e principiam com o palmeado. No decorrer das "marcas", às vezes, também há palmeado e castanholas com as pontas dos dedos. (Lima, 1954, p.36-8)

Fica evidente, então, que os olhos e ouvidos atentos desse autor distinguiram esse bailado do da catira e deram a ele seu primeiro e único espaço na literatura até então. A partir do estudo de Lima nota-se que os outros autores realmente estavam equivocados quando consideraram o fandango de chilenas como uma variação do cateretê/catira. ${ }^{12}$ Muitos desses enganos se repetem entre diversos autores e há ainda mais detalhes a pesquisar e esclarecer sobre essa questão, mas que serão apresentados em trabalhos posteriores por não serem de maior relevância aqui.

Há, ainda, uma espécie de catálogo do governo do estado de São Paulo, com data de 1975, "Folclore de São Paulo", sem autor mencionado, feito pela Secretaria de Esporte e Turismo (Biblioteca do IEB). Há aí registro da ocorrência do fandango em Capela do Alto, Cesário Lange, Itapetininga, Itararé, São Miguel Arcanjo, Sarapuí, Sorocaba e Tatuí. Todas essas cidades pertencem à região em que até hoje se praticam os fandangos caipiras.

Como se pode notar, há muita confusão na bibliografia e parece que dessa baralhada advém a escassez de estudos sobre os fandangos caipiras. Para sanar parte dessa confusão e suprir uma fração dessa lacuna bibliográfica, estamos elaborando um estudo aprofundado sobre os fandangos caipiras em nossa dissertação de mestrado.

Antes de chegar ao ponto central deste texto, as transformações dos fandangos de chilenas no tempo, descreveremos as características fundamentais dos fandangos de chilenas, apoiados nos registros feitos por Lima (1954) e principalmente nas transcrições musicais das danças praticadas atualmente (Sanches, 2012).

\section{O fandango de chilenas}

Fandango de chilenas é um conjunto de danças de sapateados e palmeados, encontrados atualmente nos municípios de Angatuba, Campina do Monte Alegre, Capela do Alto, Itapetininga e Tatuí, todas situadas no estado de São Paulo, macrorregião de Sorocaba, região sudoeste paulista.

Era prática comum entre os tropeiros que transportavam mulas do Rio Grande do Sul para as feiras de Sorocaba. Dizem que esses tropeiros costumavam dançar o fandango em volta das fogueiras para esquentar o frio e como forma de diversão.

A indumentária dos grupos é comum: usam calças compridas, camisas, chapéus em estilo country estadunidense, lenço no pescoço, botas nos pés e esporas com três discos lisos, sem dentes, que funcionam como as platinelas de um pandeiro. Essas roupas são seus uniformes, portanto cada grupo tem suas cores de camisas e lenços próprias, sendo as calças de todos, normalmente pretas. 
Os grupos têm, obrigatoriamente, número par de dançadores, pois algumas marcas são feitas em pares. ${ }^{13}$ Já o número de violeiros é variado, é necessário pelo menos um para haver fandango, mas não há um número máximo deles.

Sua instrumentação musical, portanto, é composta por viola caipira (afinada em cebolão $\left.{ }^{14}\right)$, palmeados, sapateados e esporas. Durante uma festa ou apresentação de fandango pode haver canções; entretanto elas não compõem o bailado, pois suas ocorrências são somente para que os dançadores descansem para a próxima rodada de danças, ou próxima marca.

As coreografias são feitas predominantemente em roda, com exceção do quebra-chifre, que é dançado em fileiras posicionadas frente a frente ${ }^{15}$ A música desses fandangos é binária simples e em cada marca há um ritmo que é repetido obstinadamente, o que chamamos de ostinato rítmico, e isso é uma das características fundamentais dos fandangos de esporas. Essa repetição incessante tem duração variada, pois ela depende totalmente do mandador, que é a figura que coordena a execução da dança, instruindo o grupo para que todos comecem e terminem as coreografias simultaneamente. Para garantir essa sincronia, há uma convenção rítmica chamada de "corte", que chama a atenção do ouvinte por quebrar a sequência de ostinato rítmico, o corte é apresentado ao início e ao final de cada marca a pedido do mandador (Sanches, 2012).

A partir de audição, observação e várias transcrições musicais, identificamos padrões formais comuns nos fandangos de esporas, pois as danças de todos os grupos têm uma forma musical básica semelhante: 1 - iniciam com a viola caipira sozinha; 2 - começam os palmeados; 3 - realizam o corte; 4 -iniciam a coreografia que caracteriza a marca em exposição; 5 - encerram com o corte novamente.

A partir dessa estrutura comum entre todos os grupos, nota-se também uma diferença no Grupo de Fandango de Chilenas dos Irmãos Lara, de Capela do Alto, que realiza estalos com os dedos, ou castanholas, antes dos palmeados.

Encontramos entre os grupos pesquisados as seguintes marcas praticadas atualmente: Varginha Simples, Varginha Parmeada (palmeada), Mandadinho, Quebra-Chifre, Cerradinho, Pula-Sela, Bate na Bota, Passo da Tropa, Vira Corpo, Palmeadinho, Corta Jaca, Tiguera, Marcha da Tropa (igual a Passo da Tropa) e Dança do Pulinho. Lima (1954) registrou algumas dessas marcas em suas pesquisas.

\section{Transformações no tempo}

Com o depoimento dos fandangueiros atuais e nossas observações, aprendemos que os fandangos caipiras, apesar de carregarem muitas características ancestrais, passaram por várias transformações ao longo do tempo, bem como interagem com a contemporaneidade. Isso é típico das manifestações folclóricas, pois elas são dinâmicas: carregam em si traços do passado, porque mantêm formas de expressão atávicas; trazem sinais do presente, porque dialogam com as estruturas sociais vigentes e integram suas superestruturas ideológicas; relacionam-se com o futuro, porque estão em constante transformação (Carneiro, 1965). 
Os grupos de fandango que se mantêm ao longo do tempo com número significativo de integrantes são os que mantêm a hereditariedade da dança, pois a grande maioria dos fandangueiros aprendeu a tradição de seus pais, tios ou avós. Em consequência, muitas vezes, os que não resistem e vão definhando ao passar dos anos são os grupos nos quais os descendentes dos dançadores não se interessam pela prática.

Há outros fatores que causaram a redução do número de grupos de fandango. Pelo que tudo indica, os principais deles foram o fim da pequena propriedade e o estímulo ao agronegócio, que forçaram ao êxodo rural e dispersaram comunidades rurais inteiras. Isso causou a extinção de muitas festas comunitárias e a diminuição considerável dos mutirões que eram aglutinadores sociais importantes nos quais havia fandango, como mostram pesquisas que citaremos adiante. Sabe-se, no entanto, que muitas manifestações resistiram ao êxodo rural e se mantêm fortes em algumas cidades, como é o caso do fandango de chilenas em Capela do Alto, por exemplo. No entanto, apesar de a maioria de os fandangueiros que encontramos residir em zona urbana, há que concordar que é bastante reduzido nos dias de hoje o número de grupos atuantes.

A conversão de muitos dos fandangueiros ao pentecostalismo também reduziu muito alguns grupos, pois, além de haver intolerância quanto à mitologia católica, na maioria das religiões pentecostais existe também a opressão à expressão corporal através das danças e a sugestão de que essas práticas são uma manifestação do distanciamento de Deus. É sabido que o caipira, em suas raízes, possui fé católica bastante acentuada, bem como promove festas, promessas e devoções aos santos católicos. Os fandangueiros normalmente são convidados para participar desses eventos. Em entrevista sobre por que alguns dançadores haviam parado de dançar, o dançador Pinhé, de Itapetininga, me disse: “Fulano', virou de religião e daí parou de dançar. Essa religião de crente acabou com a diversão do povo!" e "A mulher manda nele! Agora ele não dança mais, porque ela não gosta!". Em conversa com outros dançadores, a história se repetia. Portanto, questões de fé e familiares também foram motivos para que o número de dançadores diminuísse.

Os fandangos caipiras, assim como catira, jongo, congado ou tantas outras manifestações culturais produzidas hoje, não são iguais aos de há cem anos, pois, além das mudanças sociais que ocorreram, há a natureza oral de suas transmissões. Entende-se que as culturas são dinâmicas e permeáveis e exatamente por isso transformam-se, misturam-se e reinventam-se, sempre.

Em se tratando de cultura, reparamos que um mais um nem sempre é igual a dois. A cultura resultante nunca é exatamente o produto das fusões de duas outras, ela traz sempre elementos que são criados pela mistura ou pela subtração e que escapam ao domínio de uma e outra matriz. A própria música popular e folclórica brasileira nos mostra isso. (Vilela, 2013, p.156) 
Destacaremos, então, algumas mudanças ocorridas nos fandangos caipiras a partir dessa característica de permeabilidade e dinâmica cultural.

Em Itapetininga temos um caso notável, pois tradicionalmente na cidade não se utilizavam esporas para dançar; entretanto os fandangueiros as vestem desde que conheceram um dançador de Angatuba, onde sempre se usaram esporas.

O Grupo de Fandango Benedito Leite, de Angatuba, atualmente realiza a marca "marcha da tropa" que foi aprendida do Grupo de Fandango de Chilena dos Irmãos Lara, através de encontros no "Revelando São Paulo" 16 e do DVD O Fandango de Chilenas dos Irmãos Lara (2007).

Esses fatos nos mostram como não somente as interações espontâneas e vicinais, mas as interferências de cunho político e o uso de tecnologias podem contribuir para a interação entre grupos e a dinamização cultural, o que seria mais difícil e menos intenso sem esses facilitadores.

Outro fato notável no grupo de Angatuba é que, antigamente, somente os homens dançavam o fandango; mas, desde seu ressurgimento, que explicaremos adiante, mulheres são bem-vindas. O mesmo acontece com o Grupo Nossa Senhora Aparecida, de Itapetininga, que - apesar de não conter mulheres atualmente - nunca proibiu a participação delas. É muito significativo o fato de os únicos grupos da região que permitem a presença de mulheres são os que sofreram risco de extinção. Assim, o interesse em manter a tradição local prevaleceu sobre o sexismo, tão presente na cultura caipira.

A dificuldade de permanência de alguns grupos deveu-se também às mudanças na função social do fandango, pois - pelo que contam os fandangueiros e encontra-se registrado em pesquisas sobre o caipira - esse bailado era um dos principais divertimentos dessa região. Em Itapetininga, quando perguntava aos entrevistados sobre o que é o fandango, quase sempre recebia respostas como "fandango é uma diversão dos antigos" ou "fandango é uma diversão de antigamente". Portanto, o fandango possuía função de sociabilizar e estava presente em quase todas as festas na roça, em dias santos, após mutirões, ou como pretexto para reunir pessoas. Dançavam com as roupas que estivessem em seus corpos: os homens com botas, calças e camisa e as mulheres com vestidos; além disso - como atesta em entrevista o violeiro Júlio Cleto, de Tatuí - os grupos de fandango sequer tinham nomes.

No livro Os parceiros do Rio Bonito, Antonio Candido (2001, p.98) faz referência ao fandango após rezas caseiras e festas religiosas. E, ainda, no livro de Lisboa (2002, p.53), sobre o fandango em Angatuba: "O casamento foi inesquecível, mesa farta, fandango e baile a noite toda". E mais: "No anoitecer, após a 'lida' [após um mutirão], o beneficiário oferecia um jantar, dando início ao fandango, que atravessava noite adentro. Sempre fandango!” (Lisboa, 2002, p.84)

Atualmente, para a maioria dos dançadores, já não há mais essa função única de diversão e as danças são como outras atividades artísticas profissionais. 
Muitos grupos se encontram para ensaiar, possuem uniformes, cobram cachê para se apresentar e já não saem para dançar se não houver um pagamento em dinheiro. Continua havendo uma função social, pois as pessoas se interessam em assistir ao fandango e, por onde os dançadores passam, fica-lhes o status de artistas. E isso lhes interessa. No entanto, o fandango já não tem o poder de reunir pessoas gratuitamente para que se divirtam. Divertem-se, mas somente quando são contratados.

Tal fato não é de responsabilidade exclusiva dos fandangueiros, mas também da sociedade que foi progressivamente perdendo o interesse nas manifestações culturais de suas raízes. Segundo os dançadores e tocadores entrevistados, as pessoas foram trocando o fandango pelas danças de salão, onde era permitido dançar em pares. Dessa forma, gostavam somente de assistir a essas danças e não mais dançá-las. Os fandangueiros passaram a ser artistas que são convidados para se apresentarem e, assim, o fandango para eles tomou outro significado.

Em outras manifestações culturais, processos similares ocorrem, pois os homens que mantêm essas tradições ancestrais, como todos os outros, vivem a sua contemporaneidade. "A ideia de continuidade simples das formas culturais, ao longo do tempo, também é encarada com reserva pelos historiadores. Descobrem-se, por exemplo, mudanças importantes de significação apesar de certa constância das formas" (Travassos, 2007, p.144).

O fandango se distanciou daquilo que parecia ser há 30 ou 40 anos: uma dança muito conhecida e popular, pois hoje em dia a maioria dos jovens habitantes dos municípios nos quais ele está presente não o conhece. Em setembro de 2012, tive a oportunidade de acompanhar os dançadores de Itapetininga em três escolas municipais diferentes, onde se apresentaram para crianças que não apenas gostaram muito do que viram e ouviram, como até mesmo evidenciaram claro interesse em aprender aquele tipo de manifestação cultural.

Essa experiência mostrou que, apesar de ter passado por uma fase de anonimato social, é possível que o fandango retome o fôlego e volte a ser cultivado onde está ameaçado de extinção. Para isso, seria necessário um esforço do poder público, pois os dançadores reclamam que na cidade não há espaço adequado para ensaiarem ou ensinarem a outras pessoas e, na verdade, nem sabem como organizar esse tipo de ação, já que nem sempre os interessados em aprender são seus vizinhos, mas moram em bairros distantes. Há muitas outras manifestações populares que se reergueram através de apoios externos, como o jongo:

No final do século XX, uma série de fatores convergiu para a revitalização das atividades dos jongueiros - relevância da cultura expressiva nos movimentos sociais, transformações no mercado de música popular, redescoberta da cultura popular tradicional por estudantes e artistas, políticas do patrimônio imaterial do Estado brasileiro. O jongo atualiza-se, não por inércia, mas porque é recriado em resposta a situações específicas - como outras expressões simbólicas. (Travassos, 2007, p.143) 

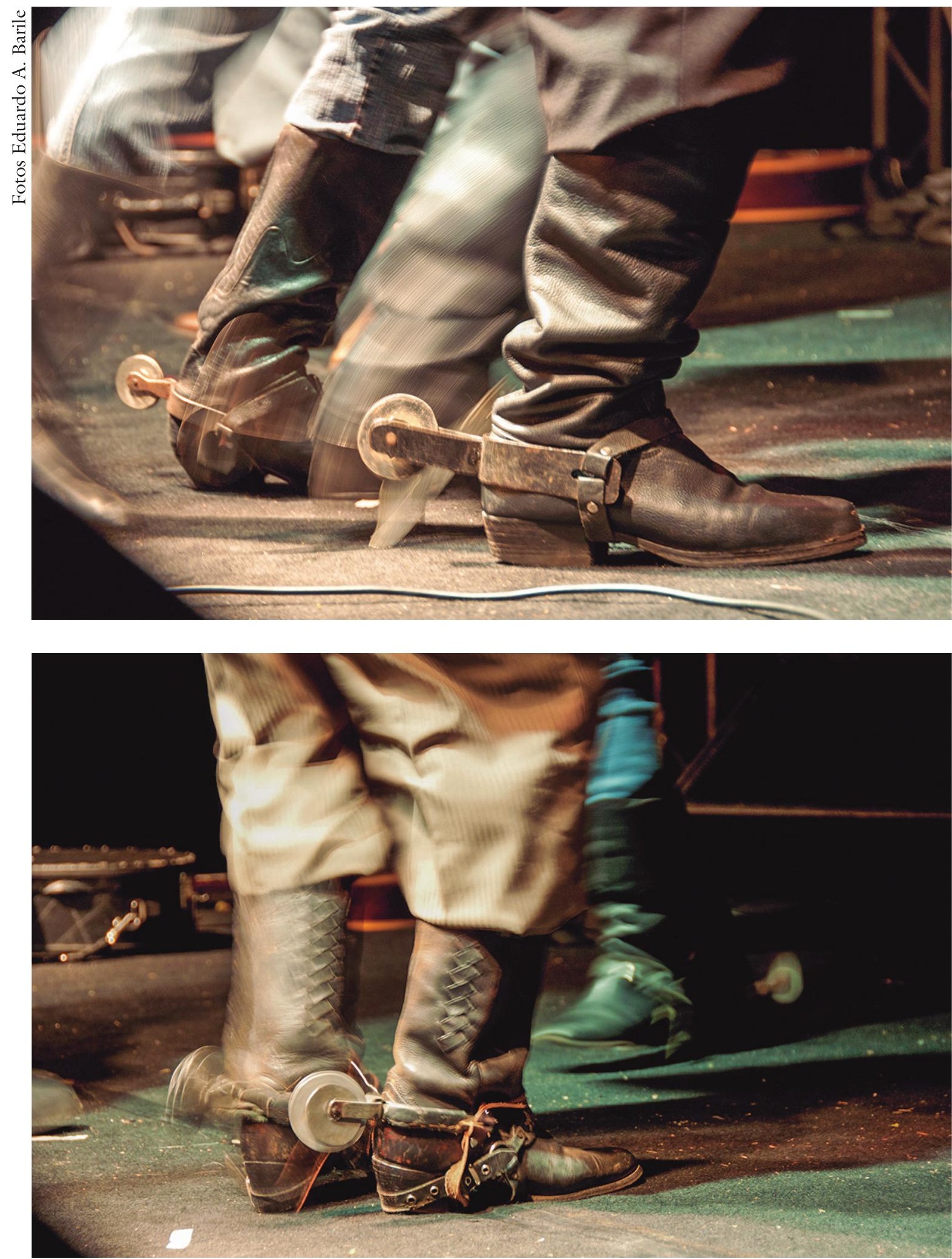

Fandango de chilenas de Itapetininga (SP). 
Temos também um exemplo bastante significativo de renascimento de um grupo de fandango, quando em Angatuba a dança ressurgiu a partir do movimento que um estudo acadêmico sobre o fandango causou na comunidade estudada. O Grupo de Fandango Benedito Leite surgiu em 2002 por iniciativa do fandangueiro Benedito Leite que ensinou seus netos e netas, uma delas com quatro anos de idade, a dançarem o fandango, com o intuito de homenagear a professora Maria Aparecida Lisboa (2002), autora do livro Fandango do Miliano. Outras crianças e adultos se interessaram em aprender o fandango a partir dessa primeira apresentação com seus netos, que acompanhados pelo violeiro Joinha, membro do antigo grupo do Bairro dos Leite juntamente com Benedito. Esse evento, então, marca o ressurgimento da dança ali. O grupo, inicialmente, era chamado de Grupo de Fandango Mirim do Bairro dos Leite e recebeu o nome de Benedito Leite após o seu falecimento.

Esse tipo de grupo já aparece com significado diferente do seu ancestral, pois os dançadores jovens e crianças muitas vezes nem chegaram a conhecer os grupos de seus antepassados dançando, tendo como referência única os ensinos de somente um ou dois dançadores. A dança não faz parte de seu cotidiano e aí, da mesma forma que nos grupos mais tradicionais que nunca tiveram suas atividades interrompidas, surge apenas com o fim de apresentar-se em palcos e com o intuito de ser guardião de uma tradição cultural local.

É possível que, com a adoção de medidas exógenas que promovam a continuidade ou ressurgimento de grupos de fandango, algumas de suas características se transformem, pois as culturas do homem do campo e do citadino globalizado se permearão, naturalmente. $\mathrm{O}$ fato de notarmos nos grupos de fandango e catira o uso de vestuários claramente advindos do modelo cowboy estadunidense, como os chapéus e as grandes fivelas nos cintos, através da globalização, reforça essa ideia.

Outro fato curioso que aponta traços da pós-modernidade entre os fandangueiros foi perceber no chapéu em estilo cowboy de um dos dançadores uma faixa onde estava escrito Underwear (roupa íntima). Nota-se aí uma característica muito interessante da cultura rural e suburbana, que é a fetichização de produtos industrializados e do reaproveitamento deles, pois é comum vermos latas, panelas, garrafas e outros utensílios reutilizados de maneira diversa, quando já não servem mais para sua função original (Martins, 2015). São transformados em vasos de flor, regadores, canecas e, no caso mencionado, o elástico de uma cueca que virou a faixa de um chapéu com um escrito em inglês. Martins (2015, p.34) trata desse fenômeno e percebe que, nesses casos, o atrativo para o usuário é a forma e a cor das letras, mesmo que não se entenda a língua: "Por toda parte, na zona rural ou na periferia pobre das grandes cidades, é possível ver frases e palavras em inglês que aí chegam com a globalização como signos da modernidade: chega a palavra, mas não chega a língua nem chega o significado". 
Assim, o fandango de chilenas é uma manifestação tradicional de grande importância para a formação cultural da região sudoeste paulista desde a época em que por aí passaram os primeiros tropeiros com suas tropas de mulas vindas do Rio Grande do Sul. Ele é dinâmico e está em constante intercâmbio com a sociedade na qual se manifesta, em um fluxo contínuo de influências recíprocas, como ocorre em todas as manifestações folclóricas (Carneiro, 1965). Mesmo que sejam mais numerosas e notáveis as influências que recebe o fandango através da globalização e dos meios de comunicação, percebe-se que, na medida em que se transforma, transforma também a maneira como a sociedade se relaciona com ele.

\section{Notas}

I Em toda a literatura sobre o fandango, incluindo Fryer (2000), os autores indicam a existência de apenas três manifestações assim denominadas no Brasil. Incluímos então os fandangos caipiras, que estão ignorados nesses textos.

2 Chilenas são esporas sem dentes usadas especialmente para dançar o fandango. Soam como as platinelas de um pandeiro.

$3 \mathrm{Na}$ zona rural de Itapetininga há um grupo que dança o fandango sem esporas ou tamancos nos pés e utiliza somente as botinas para sapatear. É o único grupo da região que dança assim e, possivelmente, o último que ainda dança sem esporas. Por não haver um nome que distinguisse esse tipo de fandango, nomeei-o como fandango de botinas.

4 Tamancos feitos de pau de laranjeira. Esses calçados se parecem mais com chinelos, pois são completamente planos, mas possuem na parte traseira um corte horizontal no meio do solado que faz que a madeira se choque consigo mesma e, assim, amplifique o som do sapateado.

$5 \mathrm{~A}$ única diferença é o uso ou não de esporas, pois musicalmente são muito semelhantes em suas estruturas formais, rítmicas e harmônicas. Portanto, daremos foco somente ao fandango de chilenas, sabendo que estarão contemplados os fandangos de botinas também. Para mais detalhes sobre os fandangos de botinas, ver Sanches (2012).

6 A pulsação da dança é composta (subdivisão dos tempos é múltipla de três), enquanto dos outros fandangos caipiras é simples (subdivisão dos tempos é múltipla de dois). Além disso, a instrumentação conta com o acordeom, além da viola, e há canções simultâneas aos sapateados; nada disso ocorre nos outros fandangos caipiras.

7 Encontramos somente um grupo de fandango de botinas, na zona rural de Itapetininga. Não há nenhuma referência a esse fandango na literatura e sua projeção não ultrapassa os limites do município. Já o fandango de tamancos, apesar de ser dançado somente por um grupo também, está muito bem estruturado, participa de festivais, encontros de folclore, possui uma associação, enfim, está organizado politicamente, entretanto também não foi estudado a fundo.

8 Marcas são as diferentes formas de músicas e danças que compõem os fandangos.

9 Cateretê e catira são tratados na literatura como sinônimos. Trata-se de uma dança de sapateados e palmeados, presente em toda a região da Paulistânia [colonizada pelas bandeiras paulistas, a Paulistânia é a região que hoje conhecemos como os estados de 
São Paulo, Mato Grosso do Sul, Goiás, bem como partes dos estados adjacentes a eles: Minas Gerais, Mato Grosso, Tocantins e Paraná (Vilela, 2013)]. Na pequena bibliografia existente, o termo cateretê é mais recorrente, no entanto não encontrei grupos que utilizassem essa palavra para designar a dança que praticam atualmente, pois a expressão usual é catira. Cateretê, hoje em dia, é mais utilizado pelos violeiros para designar um ritmo muito usado por compositores da Música Caipira, nesse caso não se trata da dança. A título de exemplificação citaremos alguns "cateretês de gravação": "Caminheiro" (Jack), "Eu, a viola e Deus" (Rolando Boldrin), "Porta do mundo" (Peão Carreiro e Zé Paulo), "Moda da mula preta” (Raul Torres).

10 Botim: Bota de cano curto, o qual termina logo após o tornozelo (Dicionário Aurélio).

11 Instrumentos idiofones são os de percussão que têm o som produzido pela vibração do seu próprio corpo, como pratos, clavas, triângulo etc.

12 Sobre as diferenças e semelhanças entre os fandangos caipiras e o catira, confira: Sanches (2017).

13 Em Campina do Monte Alegre encontramos apenas um dançador, remanescente de um grupo de quatro integrantes. Ele é o único dançador solo que encontramos, mas isso é consequência da carência de pares para o bate-pé.

14 Cebolão é a afinação de viola caipira mais utilizada pelos caipiras. Encontramos, nos fandangos caipiras, violas afinadas em Dó, Ré e Mi maior. Do primeiro para o quinto par as notas da tríade maior se organizam assim: Fundamental $-5^{\mathrm{a}}-3^{\mathrm{a}}-$ Fundamental $-5^{\text {a }}$. Convém, entretanto, assinalar o uso desta afinação, pois há muitas afinações pelo Brasil afora.

15 Há um único grupo que dança predominantemente em fileiras opostas. É o grupo de Angatuba. Não conseguimos rastrear a origem desta distinção, entretanto os fandangueiros de lá afirmam que sempre dançaram assim.

16 Principal festival da cultura paulista. Promoveu mais de 50 edições durante 18 anos e foi um importante ponto de encontro para os grupos de cultura tradicional paulista. Disponível em: <http://www.abacai.org.br/revelando-interno.php?id=281 >. Acesso em: 2 maio 2017.

\section{Referências}

AlvarengA, O. Música Popular Brasileira. 2.ed. São Paulo: Duas Cidades, 1982.

ANDRADE, M. Dicionário Musical Brasileiro. Coordenação: Oneyda Alvarenga, 198284, Flávia Camargo Toni, 1984-89. Belo Horizonte: Itatiaia; [Brasília-DF]: Ministério da Cultura; São Paulo: Instituto de Estudos Brasileiros da Universidade de São Paulo: Editora da Universidade de São Paulo, 1989. (Coleção Reconquista do Brasil. 2. Série: v.162)

ARAÚJO, A. M. Documentário Folclórico Paulista. São Paulo: Prefeitura do Município de São Paulo, Departamento de Cultura, Divisão do Arquivo Histórico, 1952.

Folclore Nacional II: danças, recreação e música. 3.ed. São Paulo: Martins Fontes, 2004.

CANDIDO, A. Os parceiros do Rio Bonito: estudo sobre o caipira paulista e a transformação dos seus meios de vida. São Paulo: Duas Cidades; Ed. 34, 2001. 
CARNEIRO, E. Dinâmica do folclore. Rio de Janeiro: Civilização Brasileira S.A., 1965.

CASCUDO, L. C. Dicionário do Folclore Brasileiro. 1l.ed. São Paulo: Global, 2002.

CÔRTES, P.; LESSA, B. Manual de Danças Gaúchas. 2.ed. São Paulo; Rio de Janeiro: Irmãos Vitale Editores, 1961.

FERRERO, C. B. A viola no fandango de Iguape e Cananéia. In: DIEGUES, C. (Org.) Enciclopédia Caiçara, v.5: festas, lendas e mitos caiçaras. São Paulo: Hucitec, 2006. p.315-23.

FRYER, P. Rhythms of resistance: African musical heritage in Brazil. London: Pluto Press, 2000.

GIFFONI, M. A. C. Danças Folclóricas Brasileiras e suas aplicações educativas. 3.ed. São Paulo: Melhoramentos; Brasília: INL, 1973.

LIMA, R. T. Melodia e ritmo no folclore de São Paulo. São Paulo: Ricordi, 1954.

LIMA, R. T. et al. O folclore do litoral norte de São Paulo. Rio de Janeiro: MEC-Seac-Funarte: Instituto Nacional do Folclore; São Paulo: Secretaria de Estado da Cultura; Universidade de Taubaté, 1981.

LISBOA, M. A. M. Fandango do Miliano: Do couro ao café, ao algodão e à pecuária leiteira: reconstrução da trajetória de surgimento e transformação da realidade sociocultural no sudoeste de São Paulo. Itu: Editora Ottoni, 2002.

MARTINS, J. S. A sociabilidade do homem simples: cotidiano e história na modernidade anômala. 3.ed., 3.reimp. São Paulo: Contexto, 2015.

PIMENTEL, A.; GRAMANI, D.; CORRÊA, J. (Org.) Museu vivo do Fandango. Rio de Janeiro: Associação Cultural Caburé, 2006.

PINTO, I. C. Fandango do Paraná. Partitura. Brasil. Editora UFPR, 1992.

SANCHES, B. S. O fandango caipira da Região de Itapetininga. 2012. 128f. TCC (Bacharelado em Música) - Departamento de Música da Escola de Comunicações e Artes, Universidade de São Paulo. São Paulo, 2012.

. Sapateados caipiras: Semelhanças e diferenças entres os fandangos caipiras e o catira In: XXVII CONGRESSO DA ASSOCIAÇÃO NACIONAL DE PESQUISA E PÓS-GRADUAÇÃO EM MÚSICA, Campinas. Anais... Campinas, 2017.

TRAVASSOS, E. Tradição oral e história. Revista de História, São Paulo, n.157 (Terceira Série), p.129-52, $2^{\circ}$ semestre de 2007.

VILELA, I. Cantando a própria história: Música caipira e enraizamento; prefácio Alfredo Bosi. São Paulo: Editora da Universidade de São Paulo, 2013.

Referências fonográficas e audiovisuais

AMANHECER CAIPIRA. Produção de Deise d'Oliveira, Kazuo Watanabe, e Rodrigo Camargo. DVD, 50 min. Tatuí: Programa de Ação Cultural, Secretaria de Estado da Cultura, Governo do Estado de São Paulo. 2008.

CANTADORES: O Folclore de Sorocaba e Região. Os Tropeiros da Mata (Grupo de 
Fandango). Sorocaba: Produção Independente, 2000. Compact Disc. Produzido por: Carlos Carvalho Cavalheiro.

DOCUMENTO SONORO DO FOLCLORE BRASILEIRO: v.4. Tropeiros da Mata (Grupo de Fandango). Gravadora: Funarte / Atração Fonográfica / Instituto Itaú Cultural. Produtor: Campanha de Defesa do Folclore Brasileiro / Instituto Nacional do Folclore. Primeiro disco: 1982/ Compact Disc: 1998.

FANDANGOS CAIPIRAS. Vitor Scarpelli (diretor). Produção de Bruno Sanches. DVD, 50 min. São Paulo: Programa de Ação Cultural, Secretaria de Estado da Cultura, Governo do Estado de São Paulo. 2012.

FANDANGO DE TAMANCO - CULTURA VIVA DO INTERIOR PAULISTA. Jaime Rafael e Diogo Araújo Silva (diretores). Produção de Diogo Araújo Silva. DVD,. Ribeirão Grande: Programa de Ação Cultural, Secretaria de Estado da Cultura, Governo do Estado de São Paulo. 2015.

O FANDANGO DE CHILENAS DOS IRMÃOS LARA. Tríade Produções. Produção de Marcelo Domingues, Edu Gomes. DVD, 50 min. Capela do Alto: Programa de Ação Cultural, Secretaria de Estado da Cultura, Governo do Estado de São Paulo. 2007.

RESUMO - O fandango de chilenas é um dos três tipos de fandangos que classificamos como "fandangos caipiras". Esses foram ignorados pela maioria dos principais folcloristas brasileiros. Como consequência disso, não houve, além do trabalho de Rossini Tavares de Lima (1954) sobre os fandangos de chilenas, pesquisas relevantes do ponto de vista social ou musical sobre essas manifestações. Mostramos aqui a principal causa dessa lacuna bibliográfica e apresentamos uma breve descrição tanto do fandango de chilenas quanto das transformações que ocorreram com o passar do tempo, desde a última vez em que se falou dele com pertinência, a década de 1950.

PALAVRAS-CHAVE: Fandangos de chilenas, Fandangos caipiras, Folclore paulista, Transformações das tradições no tempo.

ABSTRACT - The fandango de chilenas [fandango with spurs] is one of the three types of fandangos that we classify as "caipira" fandangos and which were ignored by most leading Brazilian folklorists. As a consequence, no relevant social or musical research on these manifestations has been done, other than the work of Rossini Tavares de Lima (1954) on fandangos de chilenas. We will show here the main cause of this bibliographical gap, as well as a brief description of fandango de chilenas and the transformations that have occurred over time, since it was last mentioned pertinently in the 1950s.

KEYWORDS: Fandangos de chilenas, Fandangos caipiras, São Paulo folklore, Transformations of traditions over time.

Bruno de Souza Sanches é mestrando em Etnomusicologia no Departamento de Música da Escola de Comunicações e Artes da USP. @ - brunossvio@gmail.com

Recebido em 19.6.2017 e aceito em 17.7.2017.

I Departamento de Música, Escola de Comunicação e Arte, Universidade de São Paulo, São Paulo, São Paulo, Brasil. 